CARTA AL EDITOR

\title{
La pandemia y la investigación odontológica en Chile.
}

\section{The pandemic and dental research in Chile.}

\author{
Ricardo Cartes-Velásquez ${ }^{*}$
}

1. Universidad Andrés Bello, Chile.

${ }^{*}$ Correspondencia a: Dr. Ricardo Cartes-Velásquez. | Dirección: Beltrán Mathieu \#7, Concepción, Chile. | Código postal 4070395. | Email:

cartesvelasquez@gmail.com.

Trabajo recibido 07/06/2020

Aprobado para su publicación 20/07/2020.
La odontología se ha visto profundamente afectada por la pandemia COVID-19(1), pero no solo la práctica clínica y la educación odontológica, también afectará la investigación. Esto se materializará en una disminución de la producción científica y de la empleabilidad de investigadores, así como la formación de postgrado.

Pero la pandemia también abrirá nuevas líneas de investigación para atender los problemas de la profesión a nivel local. No debemos olvidar que la mejor evidencia en China, Estados Unidos o España, no necesariamente es la mejor evidencia en Chile. Dicho lo anterior, existen 5 áreas donde las ciencias odontológicas chilenas pueden y deben seguir desarrollándose en estos tiempos de pandemia:

1. Normas de bioseguridad: Es necesario evaluar qué acciones y elementos deben componer los protocolos para nuestra realidad nacional, especialmente considerando la escasez de elementos de protección personal y la baja prioridad que se dará a la atención odontológica.

2. Situación laboral: Varios reportes en los últimos 10 años han dado cuenta de la sobreoferta profesional y las malas condiciones laborales ${ }^{(2)}$. La pandemia ha agudizado esta situación, dejando en un segundo plano a la salud bucal. Esto hace necesario evaluar estrategias para facilitar la inserción y/o reconversión laboral, especialmente de los recién titulados.

3. Educación odontológica: Las antiguas dinámicas de nuestra formación profesional tienen una escasa compatibilidad con la situación actual. Las estrategias pedagógicas requieren una evaluación urgente, que informe qué cambios son necesarios y posibles de realizar en el corto y mediano plazo.

4. Rol del dentista: El dentista es un profesional de la salud, que tiene una formación básica que le permite integrarse como un miembro activo en el enfrentamiento de la pandemia. Aquí se hace necesario evaluar qué acciones son las más apropiadas que realice el dentista y qué capacitaciones necesita para ello.

5. Epidemiología bucal: Más allá de los protocolos de bioseguridad y la crisis económica, debemos considerar que la salud bucal perderá prioridad ${ }^{(3)}$ y esto empeorará los indicadores de morbilidad en nuestro país. Urge el diseño, evaluación y mejoramiento de planes efectivos y eficientes que eviten tirar por la borda las mejoras logradas por nuestro país en materia de salud bucal(4).

La pandemia ciertamente generará cambios en la investigación odontológica, pero ello no implica que las ciencias odontológicas deban resignarse y renunciar a la posibilidad de seguir siendo un aporte a la salud bucal y la calidad de vida de todos.

\section{Bibliografía}

1. Centro de Epidemiología y Vigilancia de las Enfermedades Orales (CEVEO) La Odontología en los tiempos del coronavirus-COVID-19. Int J Interdiscip Dent. 2020;13(1): 2. DOI: http://dx.doi.org/10.4067/S2452-55882020000100002.

2. Cartes-Velásquez RA. Exponential growth of dental schools in Chile: effects on academic, economic and workforce issues. Braz Oral Res. 2013;27(6):471-7. DOI: http://dx.doi.org/10.1590/S1806-83242013000600005.
3. Probst LF, Pucca Junior GA, Pereira AC, Carli AD. Impact of financial crises on oral health indicators: an integrative review of the literature. Cien Saude Colet. 2019;24(12):4437-4448. DOI: http://dx.doi.org/10.1590/1413812320182412.23132019.

4. Cartes-Velásquez R. Salud bucal en Chile, situación actual y desafíos futuros. Odontol Sanmarquina 2020;23(2):189-196. DOI: http://doi.org/10.15381/ os.v23i2.17764. 